pulsation in the tumour, and greater freedom of breathing. I did not see her from 1851 till 1856, when, being in London, she called to show herself, saying how well she was. The pulse in the radial had not returned; but there was no pulsation in the tumour, and only a sort of roughness in the sound of the artery. She felt confident herself of the good effect of the starving treatment.

I have taken the opportunity of your having two patients together under your eye to bring this subject before you, because of late the objections urged against venesection in excess and in improper cases have produced a fashion of decrying its use altogether, and especially in thoracic aneurism. Bleeding and starving, say they, induce debility and anæmia; that is to say, in physiological language, they lower the force of the heart, and they cause a comparative excess of fibrine over blood-discs in the blood. These are both steps towards the mode adopted by Nature to effect a cure in aneurism, and perhaps in some other diseases also. So that, I contend, not merely is it the best mode, but that it is the only honest mode, of treating aneurism of the trunk-vessels; because it is the only one we at present know consonant to reason and experience.

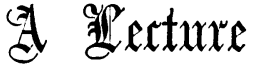

\section{ON URINARY CALCULI.}

BY

LIONEL BEALE, M.B., F.R.C.P., F.R.S.,

PHYSICIAN TO KING'S COLLEGE hOSPITAL; PROFESSOR OF PHYSI. OLOGY AND OF GENERAL AND MORBID ANATOMY IN KING'S COLLEGE, LONDON ; ETC.

[Continued from page 32.]

Summary of the Chemical Characters of Urinany Calculi.

\section{Calculi which leave only a slight Residue} after Ignition.

Uric Acid. Murexide formed when a solution in nitric acid is evaporated and exposed to the vapour of am. monia. A mere trace of residue left after ignition. Ammonia not given off when treated with a solution of caustic potash.

Urate of Ammonia. Reaction of murexide. Ammonia evolved when treated with potash.

Urate of Soda. Reaction of murexide. Fuses and gives a yellow tint to the flame. Leaves a decided residue after ignition.

Urate of Lime. Reaction of murexide. Infusible. After ignition, carbonate of lime remains.

Urate of Magnesia. Reaction of murexide. Infusible. The residue after ignition dissolves, with slight effervescence, in dilute sulphuric acid. The magnesia is precipitated from this solution, in the form of triple phosphate, upon the addition of phosphate of soda and ammonia.

Xanthine does not exhibit the murexide reaction. The solution in nitric acid turns yellow on evaporation. It is not soluble in carbonate of potassa.

Cystine is soluble in caustic ammonia, and in carbonate of ammonia. It crystallises from an ammoniacal solution in six-sided plates.

Fibrine emits an odour of burnt feathers on ignition. Solution in caustic potash precipitated by acetic acid, and also by ferrocyanide of potassium after the addition of a little acetic acid.

\section{Calculi which leave a considerable Residue} after Ignition.

Triple or Ammoniaco.MIagnesian Phosphate fuses in the blowpipe flame, and gives an ammoniacal odour. It dissolves in acetic acid without effervescence. Ammonia gives in this solution a crystalline precipitate of triple phosphate.

Phosphate of Lime does not fuse. Soluble in hydrochloric acid. Precipitated by ammonia in amorphous granules. From solution in acetic acid, the lime may be precipitated as oxalate when oxalate of ammonia is added.

Oxalate of Lime. Soluble in mineral acids, without effervescence. Precipitated from acid solution by ammonia. Insoluble in acetic acid. After ignition, residue effervesces freely on the addition of acids.

Carbonate of Lime. Soluble in acids, with effervescence. Lime precipitated from an acetic acid solution by oxalate of ammonia.

On the Origin and Formation of Urinary Calculi, and of the Nature of the Nucleus..

I have already had to refer briefly to this subject on two or three occasions. Whenever there is a tendency to the precipitation of any of the slightly soluble consti. tuents of the urine in an insoluble form before the urine has left the organism, one of the conditions most essential to the formation of calculus is present. If an unusual quantity of any such substance should be formed, so that the urine contains a stronger solution of it than in health, very slight circumstances will lead to its deposition before the urine has left the bladder, and thus insoluble deposits occur. Each little mass of deposit may form a nucleus around which new matter collects; but, as a general rule, the deposit escapes with the urine. Often it would appear that on the surface, and in the interstices, of rough stones more especially, small quantities of urine are retained, and prevented from mixing with the general mass. Chemical changes soon occur, the imme. diate result of which is the further precipitation of insoluble material. If the urine alters in its character, different substances may be deposited; thus, oxalate of lime may form the nucleus of the calculus; and, after this has reached a certain size, the deposition of the oxalate may give place to that of uric acid. Again, the precipitation of this substance may cease, and several successive layers of phosphate may afterwards be formed. In some calculi, these layers alternate in a very remarkable manner.

The most interesting part of the whole process is the formation of the vucleus, and it is most important that we should study this matter very carefully. If we were able to ascertain the existence of calculi at a very early period of their formation, we could in many cases, doubtless, promote their expulsion before they attained any size, and thus most distressing suffering would often be prevented, and sometimes the necessity for a severe operation removed.

Any solid matter may form the nucleus of a calculous concretion. Inspissated mucus from any part of the urinary organs-crystals which have been depositedcells of epithelium-ova of entozon-pieces of fibrine and small clots of blood-foreign bodies which have been introduced from without, such as peas, portions of slate pencil, or tobacco-pipe, pins and needles, and other substances which are occasionally introduced into the urethra by silly persons. A piece of a catheter and bougie have also been found in the centre of a stone.

I have lately had my attention very forcibly directed to the formation of urinary calculi, in consequence of having met with many specimens of microscopical calculi in urine. It is not at all uncommon to meet with microscopic uric acid calculi-aggregations consisting of uric acid crystals, which, if retained, might receive deposits of fresh material on the outside, until the 
small calculi, varying in size from a mustard-seed to that of a pea or larger, are formed.

Microscopical calculi of phosphate of lime are by no means uncommon, and are often found in the kidney; but until lately I had never had an opportunity of watching the formation of calculi composed of oxalate of lime. The nucleus of these calculi does not consist of mucus or epithelium, as in the phosphatic calculus ; but is of the same composition as the exterior. Fig. 54 represents a mass of dumb-bell crystals, many of which collections were passed in the urine. Although the mass is seen to consist of a number of distinct crystals, these are firmly attached, so that the whole may be rolled over and over without the individual crystals being separated from each other. Such collections I have many times seen in the uriniferous tubes in kidneys obtained from post mortem examinations, which leaves no doubt as to the precise seat of formation of these bodies. Gradually the interstices between the individual crystals be. come filled up with the same material, and at the same time a few of the larger crystals increase in size at the expense of the small ones. At length a small crystalline mass of an oval form is developed, which clearly con. sists of a microscopic mulberry calculus, and, if retained, will gradually increase in size. (Fig. 55.) Calculi of this description are represented in the plates containing specimens of calculi in the Illustrations. When such calculi reach the pelvis of the kidney, a few sometimes increase gradually by the deposition of oxalate of lime upon their exterior; while, no doubt, the greater number escape with the urine, and give no trouble. Such small bodies would easily become entangled in the mucous membrane, and might remain in the pelvis of the kidney without exciting any disturbance until they had grown so large as to cause great inconvenience. If some of them passed down the ureter into the bladder, and happened to be retained for some time in this viscus, in a case where the urine contained much oxalate, they might increase in size until too large to escape by the urethra. It is, therefore, of great importance that cases in which these dumb.bell crystals are deposited should be very carefully watched. 'This observation is of some interest also as showing the che mical composition of the dumb-bells, which has long been a disputed point.

As I have before stated, many small uric acid cal. culi, which appear to be composed entirely of this substance, will be found upon careful examination to possess a nucleus consisting of oxalate of lime, and not unfrequently by the action of liquor potassæ well defined dumb-bell crystals may be obtained. These are insolnble in potash, and also in acetic acid. I have obtained from several specimens fragments of a mass larger than that represented in Fig. 55, and no doubt formed in the same manner. From recent analyses I have made I have been led to the conclusion that the dumb-bell crystals form the nucleus, around which the uric acid is deposited, more frequently than any other substance. I have not detected oxalate of lime in the centre of the small renal calculi composed of phosphate of lime which I have subjected to examination.

\section{On the Relative Frequency of the Occurrence of the Different Calculi.}

It is often very difficult to ascertain why certain varieties of calculi should be found in greater propor. tion in some parts of the country than in others. The question is one of great interest in connexion with the consideration of conditions under which the formation of urinary calculi occurs.

In the collection of calculi at Guy's Hospital the proportion composed of phosphate of lime is as $1: 29$; at Bartholomew's as 1:32 ; while in Norwich it is as 1:132 35; and in Bristol as 1:155. Of 230 pure uric acid calculi in different hospitals in England and on the continent, as many as 164 are contained in the Nor wich collection. (See the tables in the appendix to $\mathrm{Dr}$. Prout's work on Stomach and Urinary Diseases.) In the collection of urinary calculi in the museum of Guy's Hospital, it appears, from the statement of Dr. Golding Bird, that out of 208 calculi the nucleus consisted of uric acid in 127, of oxalate of lime in 47 , of phosphates in 22 , and of cystine in 11 ; or, of uric acid in 60 per cent., of oxalate of lime in 22 per cent., of phosphates in 10 per cent., and of cystine in 5 per cent. 'These figures are somewhat different to those given by $\mathrm{Dr}$. Golding Bird, because I have thought it more correct to reckon in this calculation 142 calculi which were obtained from one individual as one.

Dr. Carter's observations on the composition of the calculi in the Grant Medical College, Bombay, prove that very few nuclei are composed of uric acid, while a large number consist of oxalate of lime. The following table, from Dr. Carter's paper, shows the per centage of calculi in India and in England entirely composed of uric acid, urate of ammonia, and oxalate of lime:Grant Med. Coll. of Guy's
College. Sorwich
Surgeons. Hospital. Hospital. Per cent. Per cent. Per cent. Per cent.

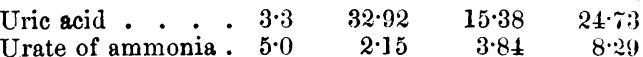

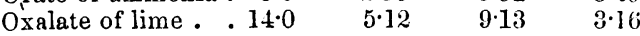

The following are the conclusions to which Dr. Carter has been led: " 1 . That, in the Bombay presidency, the proportion of calculi having oxalate of lime for their nucleus, or wholly composed of it, is about twice as great as in England, taking for comparison certain standard collections there. 2. That the proportion of calculi having uric acid, or a urate, for their nucleus or entire substance, is considerably less in India than in England; in the former, urate of ammonia calculi are somewhat more frequent than uric acid calculi; the opposite is the case in England. 3. That the number of calculi wholly composed of earthy phosphates, or having them for a nucleus, is proportionately much fewer in India than in England, the difference being chiefly owing to the rarity of the mixed phosphate in the former." (An Account of the Calculi contained in the Grant Medical College Museum, with some General Remarks on Calculi in India. By H. V. Carter, M.D.Lond., Assistant-Surgeon, Acting Curator of the Museum, Aug. 1859.)

It is, however, important to bear in mind that in the observations to which I have alluded, the central part of the calculus which is visible to the unaided eye is spoken of as the nucleus, while the real nucleus may be microscopic, and of a different composition to the material which immediately surrounds it. The nucleus of many calculi, which apparently consists of uric acid, is really composed of oxalate of lime, around which the uric acid has been deposited. This phosphatic calculus which I now show you (Fig. 59), seems to have a nucleus of uric acid about the size of an almond, but the latter contains in its centre a small nucleus consisting of oxalate, which can only be demonstrated by the microscope. Now the history of the formation of this is, probably, as follows: A number of dumb-bell crystals of oxalate of lime formed in the uriniferous tubes became aggregated together, and around this small mass uric acid was deposited as it lay in the tubes and pelvis of the kidney ; then it passed down the ureter into the bladder, where the phosphate was deposited, and where it attained its present size. Now, the deposition of the phosphatic salts on the uric acid is not more dependent on the presence of the latter than the precipitation of the uric acid was consequent upon the presence of the oxalate. In all probability neither the phosphate nor the uric acid would have been precipitated had not the oxalate been present in the first instance. It is not too much to say that if the latter had not remained for some time in the uriniferous tubes and gradually increased in size, no calculus 
would have been formed in the present case; if, therefore, the collection of dumb-bell crystals had been washed out of the kidney soon after their formation by diluents, the further precipitation of calculous matter would have been entirely prevented.

It is important that we should make numerous observ: ations on the nuclei of various calculi, and endeavour to determine their exact nature by microscopical investigation and by the application of chemical tests. In this inquiry you will find it advantageous to take the smallest calculi and examine them as soon as possible after they have been passed. After they have become dry, it is, in many cases, quite useless to attempt investigations on the nature of the nucleus.

\section{[To be continued.]}

\section{Original Communications.}

\section{SCROFULOUS DISEASES OF THE EXTERNAL LYMPHATIC GLANDS :}

THEIR NATURE, VARIETY, AND TREATMENT.

By P. C. PRICE, Esq., Surgeon to the Great Northern Hospital; the Metropolitan Infirmary for Scrofulous Children at Margate; etc.

\section{III.-Tuberculous Disease of the External Lymphatic GLands. \\ [Continued from p. 915 of volume for 1860 .]}

Cod-Liver Oil. Perhaps there is no single medicine which, during the past half century, has met with more extensive trial, and so charmed both the profession and public, as the oil derived from the cod's liver; and although its employment has not always been followed with direct and immediate benefit in all cases in which it has been prescribed, still there is no doubt that it often proves a most valuable agent. In scrofula, in various forms, the use of this oil has long been cherished. Dr. Bennett, from the pages of whose interesting work (A Trcatise on Cod-Liver Oil: J. H.Bennett, M.D., 1841) I have gathered much information, states, that this oil was used in Holland as a curative avent many years before it became familiar to the profession of this coun. try; and it was only in 1822 , a prize being offered by a learned society of Utrecht for the best essay on the chemical and therapeutical properties of the substance, that its truly wonderful efficacy in the treatment of tuberculous diseases was developed.

As I am rnainly writing from my own individual experience, I feel bound to advance in an especial manner my own impressions regarding the value of the medicine. In all stages of tuberculous manifestations of the lymphatic glands, I have generally found the administration of the oil of decided benefit, provided a sufficient quantity has been taken; but in no stage of the disease is it of such advantage as when suppuration and ulceration have weakened and impoverished the irritated system. In the earliest forms of glandular implication from tuberculous exudation, a free and persistent use of the oil is very often attended with all the beneficial results which could be desired. When there is danger of ulceration and suppuration, by reason of the degeneration of the tuberculous material, the exhibition of the oil constantly acts favourably in preventing the occurrence of such untoward events. I could quote many cases illustrative of this point, and prove that, in all probability, the wcrst results would have followed the progressive advance of the disease had not the use of the oil been maintained for a considerable period; and, doubtless, similar instances could be collected from the practice of all surgeons.
Under a diligently pursued course, the effect on the suppurating tracts of the ulcerated cavities, which are found in connexion with the destroyed gland and the skin, is often marvellous; while disappointment occasionally occurs in its administration for the cure of less formidable mischief. Many are the theories that have been advanced regarding the way in which this valuable medicine acts upon the constitution. Dr. Bennett, wło has so ably considered the subject, believes that " the modus operandi consists in stimulating the lymphatic glands and vessels, and by these means increasing the activity of the capillary system. By its action on the former, the process of assimilation is facilitated, and the appetite increased; the quality of the blood is thus im. proved; and so, lastly, the different organs and structures of the body become better nourished, and receive more turgor vitalis." In whatever manner the oil acts, it is somewhat doubtful to which of its properties the good effects are traceable. There are some practitioners who believe that it is solely valuable on accuunt of the iodine it naturally contains. This is evidently an erroneous impression, for much of the oil in everyday use contains scarcely a single trace of this valuable and efficient drug; and, moreover, it has been found that other oils, besides that obtained from the liver of the cod, are of advantage in the treatment of scrofula, although they have little or no iodine in combination. Some highly interesting observations have been made on the use of various oils in the treatment of tuberculous diseases by the late Dr. Theophilus Thompson. In his published Lettsomian Lectures, delivered before the Fellows of the Medical Society of London in 1855, Dr. Thompson recorded some extensive inquiries which he instituted regarding the relative value of many oils, such as sperm and seal oils, and those derived from the cod's liver, cocoa-nut, suntlower, neat'sfoot, etc. This gentleman believed that these various oils act by mo. difying the condition of the blood, and especially the condition of the granules which enrich the fluid, and dispose them to the calm progression of change, by which they are made to contribute to the production of bealthy structure (p. 36). I have myself had but slight experience in the use of these various oils, having found that derived from the cod's liver so highly serviceable, and even for hospital purposes sufficiently cheap.

From Dr. 'Thompson's brochure I extract the analysis of four oils which are most frequently given in tuberculous disease, as furnished by Mr. Dugald Campbell :-

Ultimate Analysis of Oils.

\begin{tabular}{l|c|c|c|c}
\hline & Carbon. & Hydrogen. & Nitrogen. & Oxygen. \\
\hline Cod-liver oil .... & 80.18 & 13.72 & 0.246 & 5.854 \\
Neats'foot oil .. & 64.33 & 12.50 & 0.064 & 23.106 \\
Cocoa-nut oil ... & 69.62 & 12.49 & 0.060 & 17.830 \\
Olive oil....... & 69.38 & 13.47 & 0.058 & 17.092
\end{tabular}

While partially agreeing in the opinion of so able a writer and observer, I cannot overlook the fact that the fatty properties of these oils have greatly to do with their value, as has been well advocated by Dr. Ascherson of Berlin. There can be no doubt that the digestive functions are rapidly amended by their use as an article of diet, independently of their therapeutical action; and that marked improvement oftentimes, I own, obtains in diseased glands and other organs when the assimilating processes are more harmoniously regulated. Dr. James Turnbull (in his Inquiry into the Curability of Consumption, 1859) states, that he believes cod-liver oil acts by promoting the solution of albuminous aliments in the stomach. Mr. Balnan, without advancing any spe. cial theory as to the action of this oil, came to the con. 